\title{
Quantum-sized effects in oxidized silicon structures with surface II-VI nanocrystals
}

\author{
L. Karachevtseva $^{1^{*}}$, S. Kuchmii $^{2}$, O. Kolyadina $^{1}$, O. Lytvynenko ${ }^{1}$, L. Matveeva $^{1}$, \\ O. Sapelnikova ${ }^{1}$, O. Smirnov ${ }^{1}$, O. Stroyuk ${ }^{2}$ \\ ${ }^{I} V$. Lashkaryov Institute of Semiconductor Physics, National Academy of Sciences of Ukraine, \\ 41, prospect Nauky, 03028 Kyiv, Ukraine \\ *Corresponding author phone: +38(044) 525-2309; e-mail: lakar@isp.kiev.ua \\ ${ }^{2}$ L. Pisarzhevskii Institute of Physical Chemistry, National Academy of Sciences of Ukraine, \\ 31, prospect Nauky, 03028 Kyiv, Ukraine
}

\begin{abstract}
The $\mathrm{Si}-\mathrm{SiO}_{2}$ interface in oxidized macroporous silicon structures with surface $\mathrm{CdS}$ and $\mathrm{ZnO}$ nanocrystals was investigated using the methods of electroreflectance and photoconductivity. The Franz-Keldysh effect, built-in electric field and surface quantization of charge carriers in the $\mathrm{Si}_{-} \mathrm{SiO}_{2}$ region were revealed. The splitting of photoconductivity peaks was detected in the area of indirect band-to-band transition due to quantization of charge carriers in the surface silicon region, too. The latter data correlate with the results of the electroreflectance spectra measurements in the area of direct interband transition of oxidized macroporous silicon structures with surface $\mathrm{CdS}$ and $\mathrm{ZnO}$ nanocrystals.
\end{abstract}

Keywords: macroporous silicon, $\mathrm{Si}-\mathrm{SiO}_{2}$ interface, $\mathrm{CdS}$ and $\mathrm{ZnO}$ nanocrystals, FranzKeldysh effect, surface quantization.

Manuscript received 16.01.14; revised version received 23.04.14; accepted for publication 12.06.14; published online 30.06.14.

\section{Introduction}

Nanotechnologies of II-VI nanocrystals in oxidized macroporous silicon structures are perspective for manufacturing light emitting elements. There were proposed the oxidized macroporous silicon structures with surface $\mathrm{CdS}$ and $\mathrm{ZnO}$ nanocrystals [1] to produce efficient light emitting elements by reducing the flow of electrons and its recombination outside the nanoparticle layer. Macroporous silicon is promising material for the development of $2 \mathrm{D}$ photonic structures with the required geometry and large effective surface [2,3]. It determines optical and electro-optical characteristics of macroporous silicon structures $[4,5]$. In $[6,7]$, we investigated the near-IR light absorption oscillations in 2D macroporous silicon structures with surface II-VI nanocrystals and $\mathrm{SiO}_{2}$ nanocoatings, taking into account the electrooptical Wannier-Stark effect within the strong electric field approximation.
In this paper, the $\mathrm{Si}_{-} \mathrm{SiO}_{2}$ interface in oxidized silicon structures with surface $\mathrm{CdS}$ and $\mathrm{ZnO}$ nanocrystals was investigated using the methods of electroreflectance and photoconductivity. The direct interband transition energy, broadening parameter and relaxation time of charge carriers were identified from the electroreflectance spectra of silicon structures with silicon oxide layer of 7 , 15 and 30-nm thickness and surface $\mathrm{CdS}, \mathrm{ZnO}$ nanocrystals. Photoconductivity spectra of silicon nanocoating "silica - nanocrystals $\mathrm{CdS}, \mathrm{ZnO}$ " and the structure of macroporous silicon with oxide layer with the thickness $30 \mathrm{~nm}$ were measured, too.

\section{Procedure}

The $\mathrm{SiO}_{2}$ nanocoatings with the thickness 7,15 and $30 \mathrm{~nm}$ were formed on silicon samples in the diffusion oven after treatment in nitrogen atmosphere and in dry oxygen for 40 to $60 \mathrm{~min}$ at the temperature $1050{ }^{\circ} \mathrm{C}$. The oxide thickness was measured using ellipsometry. 


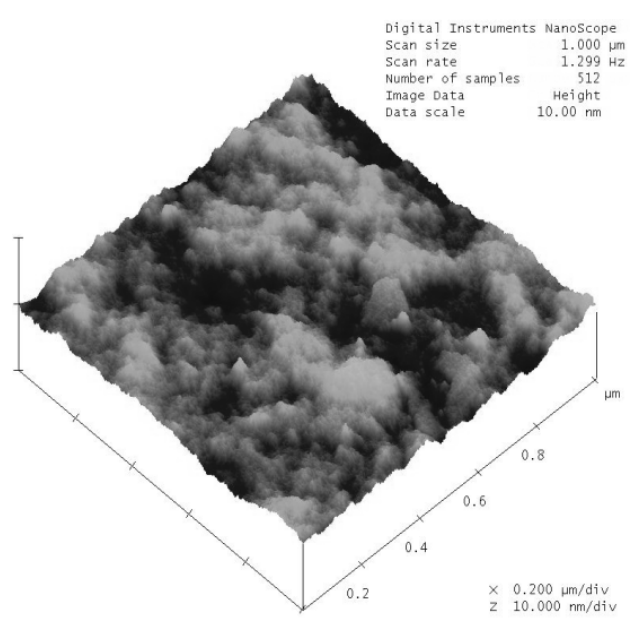

Fig. 1. Morphology of CdS nanocrystals in polyethylenimine according to AFM data.

CdS nanocrystals $(1.8 \ldots 2 \mathrm{~nm})$ were deposited onto silicon substrate from colloidal solution in polyethylenimine. The nanocrystal size values were obtained with AFM (Fig. 1). ZnO nanocrystals (5-6 nm) were synthesized in colloidal solution of $\mathrm{Zn}\left(\mathrm{CH}_{3} \mathrm{COO}\right)_{2}$ in ethanol [8]. Colloidal solution of $\mathrm{ZnO}$ nanocrystals was deposited onto silicon, and the sample was kept until complete evaporation of the solvent. The obtained sample was washed with distilled water to remove residual salts.

For the purpose of studying, the macroporous silicon samples were made using photoelectrochemical etching $[2,3]$ the $n$-silicon wafers of [100] orientation (the electron concentration $n_{0}=10^{15} \mathrm{~cm}^{-3}$ ). Macroporous silicon structures with the macropore depth $h_{p}=70 \ldots 80 \mu \mathrm{m}$, diameter $D_{p}=2 \ldots 4 \mu \mathrm{m}$ and concentration $N_{p}=(1.2-1.9) \times 10^{6} \mathrm{~cm}^{-2}$ were formed.

\section{Experimental results and discussion}

\subsection{Electroreflectance spectra}

Electroreflectance spectra of $\mathrm{Si}_{-} \mathrm{SiO}_{2}$ with nanocoatings of nanocrystals $\mathrm{CdS}, \mathrm{ZnO}$ and the original surface of the silicon substrate are shown in Figs 2 and 3 . The electroreflectance spectra were measured by the standard electrolytic technique at room temperature. It is evident from the figures that all the electroreflectance spectra correspond to silicon of $n$-type conductivity, while the electroreflectance spectra of macroporous silicon structures correspond to the surface of $p$-type conductivity silicon [5] due to its passivation by hydrogen atoms.

High-energy Franz-Keldysh oscillations [5] with the photon energy higher $3.6 \mathrm{eV}$ indicate the presence of the built-in electric field for $\mathrm{CdS}$ and $\mathrm{ZnO}$ nanocrystals on silicon oxide with the thickness 15 and $30 \mathrm{~nm}$ (Fig. 2, curves 3, 4 and Fig. 3, curves 3,4). It is possible to determine the dependence of the slope $(4 / 3 \pi) \cdot\left(E_{m}-E_{g}\right)^{3 / 2}$ on the number of oscillations, electro-optical energy and value of the built-in electric field for the thickness $15 \mathrm{~nm}$ and $30 \mathrm{~nm}$ of the oxide layer (Table 1). The energy transition $E_{g}$, spectrum broadening parameter $\Gamma$ (that characterized the structural perfection of the $\mathrm{Si}-\mathrm{SiO}_{2}$ interface) and relaxation time of the charge carrier energy $\tau=\hbar / 2 \Gamma$ were identified from electroreflectance spectra, too (Figs 2 and 3, Table 1).

The direct optical transition energy for the investigated samples varies from 3.29 to $3.38 \mathrm{eV}$ (Table 1) and is low in comparison with the direct optical transition energy for monocrystalline silicon $(3.38 \mathrm{eV})$. The energy shift may indicate the internal mechanical stresses in $\mathrm{Si}-\mathrm{SiO}_{2}$ heterosystem. The main cause of stress is a significant difference in temperature expansion coefficients of $\mathrm{Si}\left(3.1 \cdot 10^{-6} \mathrm{~K}^{-1}\right)$ and $\mathrm{SiO}_{2}$ $\left(10^{-7} \mathrm{~K}^{-1}\right)$ and, consequently, a larger volume of phases $\mathrm{SiO}_{2}$ and $\mathrm{SiO}_{\mathrm{x}}$ as compared to monocrystalline silicon. The direct optical transition energy of the unstrained silicon surface is $3.38 \mathrm{eV}$ [5]. Thus, the maximum deviation from that of the unstrained silicon surface is $90 \mathrm{meV}$ for samples with the CdS nanocoating and the oxide thickness $30 \mathrm{~nm}$ as well as for samples with the $\mathrm{ZnO}$ nanocoating with the oxide thickness $15 \mathrm{~nm}$. The reduction of the direct optical transition energy of the samples corresponds to the mechanical stress stretching of monocrystalline silicon. The shift of the direct optical transition energy can also be the result of formation of local electric field at the $\mathrm{Si}_{-} \mathrm{SiO}_{2}$ interface:

Table 1. Energy transition $E_{g}$, spectrum broadening parameter $\Gamma$, value of the built-in electric field $\boldsymbol{F}_{S}$.

\begin{tabular}{|c|c|c|c|c|c|c|c|c|}
\hline \multicolumn{2}{|c|}{$\mathrm{c}-\mathrm{Si}$} & \multirow{2}{*}{$\begin{array}{c}d_{\mathrm{SiO}_{2}} \\
\mathrm{~nm}\end{array}$} & \multicolumn{3}{|c|}{$\mathrm{CdS}$} & \multicolumn{3}{|c|}{$\mathrm{ZnO}$} \\
\hline $\begin{array}{l}E_{g} \\
\mathrm{eV}\end{array}$ & $\begin{array}{c}\Gamma, \\
\mathrm{meV}\end{array}$ & & $E_{g}, \mathrm{eV}$ & $\Gamma, \mathrm{meV}$ & $F_{S}, 10^{5} \mathrm{~V} / \mathrm{cm}$ & $E_{g}, \mathrm{eV}$ & $\Gamma, \mathrm{meV}$ & $F_{S}, 10^{5} \mathrm{~V} / \mathrm{cm}$ \\
\hline \multirow{3}{*}{3.38} & \multirow{3}{*}{92} & 7 & 3.34 & 183 & - & 3.35 & 147 & - \\
\hline & & 15 & 3.38 & 211 & 6.65 & 3.30 & 164 & 7.74 \\
\hline & & 30 & 3.29 & 228 & 3.11 & 3.33 & 203 & 4.35 \\
\hline
\end{tabular}


$\Delta F_{g}=-\left(\hbar^{2} \sigma^{2} F^{2}\right) /\left[24(k T)^{3} \mu\right]$,

where $\sigma$ is the conductivity of the surface layers of crystalline silicon. On the other hand, the shift of the main peak of photoconductivity to the high photon energy side by $170 \ldots 200 \mathrm{meV}$ was explained with account of the interband transition of electrons to the Fermi level in the conduction band.

As shown in Table 1, the broadening parameter for oxidized silicon with $\mathrm{CdS}$ and $\mathrm{ZnO}$ nanocoatings is much higher than the value of $\Gamma$ for monocrystalline silicon, indicating the influence of defects on the interface of $\mathrm{Si}_{-} \mathrm{SiO}_{2}$. The broadening parameter increases with the thickness of silicon oxide within 7 to $30 \mathrm{~nm}$ from 183 up to $228 \mathrm{meV}$ for the structures with $\mathrm{CdS}$ nanocoating and from 147 up to $203 \mathrm{meV}$ for $\mathrm{ZnO}$ nanocoating. Small values of the broadening parameter for the structures with $\mathrm{ZnO}$ nanocoating show lower defectiveness of $\mathrm{Si}_{-} \mathrm{SiO}_{2}$ boundary or higher electron localization and, consequently, higher electron relaxation time.

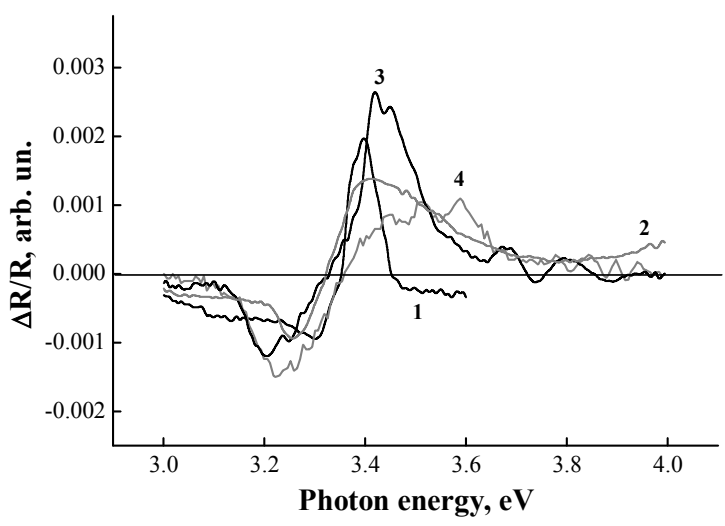

Fig. 2. Electroreflectance spectra of silicon substrate (1) and silicon structures with CdS nanocrystals on silicon oxide layer of the thickness: 7 (2), 15 (3), and $30 \mathrm{~nm}$ (4).

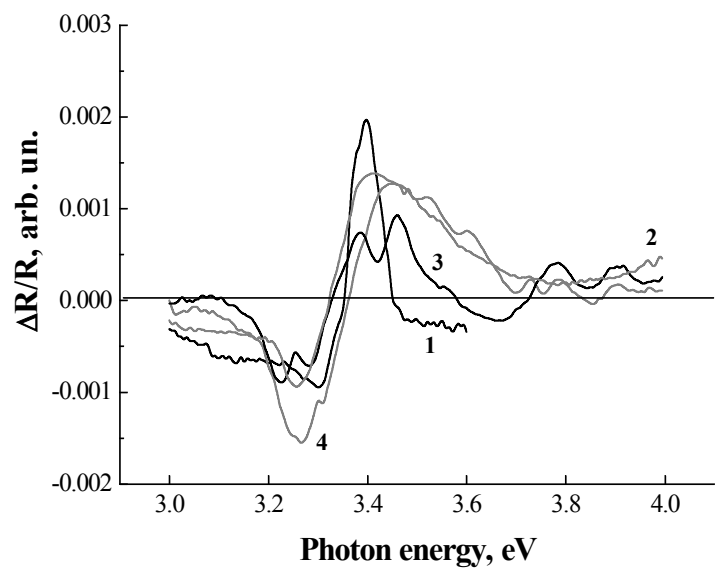

Fig. 3. Electroreflectance spectra of silicon substrate (1) and silicon structures with $\mathrm{ZnO}$ nanocrystals on silicon oxide layer of the thickness: 7 (2), 15 (3), and $30 \mathrm{~nm}$ (4).
The main electroreflectance peak (Figs 2 and 3) revealed the quantization of charge carriers in the nearsurface region of silicon and splitting of peaks corresponding to one quantized energy level near $40 \mathrm{meV}$ (oxide thickness $15 \mathrm{~nm}$ ) and two quantum levels with the energies 70 and $140 \mathrm{meV}$ (oxide thickness $30 \mathrm{~nm}$ ). The electric field $F_{S}$ (Table 2) was determined on the basis of the model of the triangular potential well [9]:

$E_{n}=\left[\frac{3 \pi \hbar e F_{S}}{\left(8 m^{*}\right)^{1 / 2}}\left(n+\frac{3}{4}\right)\right]^{2 / 3}$.

For the first and second quantum levels

$E_{0,1}=E_{1}-E_{0}=\left[\frac{3 \pi \hbar e F_{S}}{\left(8 m^{*}\right)^{1 / 2}}\right]^{2 / 3} \cdot K_{0,1}$,

where $K_{0,1}=0.626$.

$E_{1,2}=E_{2}-E_{1}=\left[\frac{3 \pi \hbar e F_{S}}{\left(8 m^{*}\right)^{1 / 2}}\right]^{2 / 3} \cdot K_{1,2}$,

where $K_{1,2}=0.511$.

The electric field intensity $F_{S}$ :

$$
\begin{aligned}
& F_{S}^{0,1}=\left[\frac{\left(8 m_{e}^{*}\right)^{1 / 2}}{3 \pi \hbar e}\right] \cdot\left[\frac{E_{0,1}}{K_{0,1}}\right], \\
& F_{S}^{1,2}=\left[\frac{\left(8 m_{e}^{*}\right)^{1 / 2}}{3 \pi \hbar e}\right] \cdot\left[\frac{E_{1,2}}{K_{1,2}}\right] .
\end{aligned}
$$

Table 2. The electron Fermi level, first quantum energy level $E_{0,1}$ and electric field $F_{S}^{0,1}$, second quantum energy level $E_{1,2}$ and electric field $F_{S}^{1,2}$ obtained from the

\begin{tabular}{|c|c|c|c|c|c|c|}
\hline 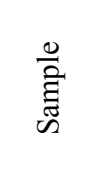 & $\begin{array}{c}d_{\mathrm{SiO}_{2}}, \\
\mathrm{~nm}\end{array}$ & $\begin{array}{l}\vec{\partial} \\
\text { if }\end{array}$ & $\begin{array}{l}\overrightarrow{0} \\
\overrightarrow{0} \\
0 \\
\dot{\overrightarrow{0}} \\
\dot{y}\end{array}$ & $=\frac{a}{0}$ & 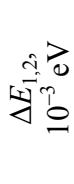 & 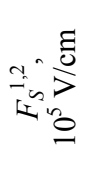 \\
\hline $\mathrm{CdS}$ & 15 & 3.41 & 36 & 0.762 & & \\
\hline $\mathrm{CdS}$ & 30 & 3.42 & 67 & 1.93 & 74 & 3.05 \\
\hline $\mathrm{ZnO}$ & 15 & 3.41 & 75 & 2.29 & & \\
\hline $\mathrm{ZnO}$ & 30 & 3.39 & 69 & 2.02 & 74 & 3.05 \\
\hline macPS & - & 3.38 & - & - & - & - \\
\hline
\end{tabular}
electroreflectance spectra. 


\subsection{Photoconductivity spectra}

Photoconductivity spectra of oxidized silicon structures with $\mathrm{CdS}$ and $\mathrm{ZnO}$ nanocrystals were measured at room temperature using a spectrometer within the spectral range $0.5 \ldots 2 \mu \mathrm{m}$. The sample parameters and measurement conditions are given in Table 3. The resistance of samples $\left(R_{\text {samp }}\right)$ was 0.2 to $10.5 \mathrm{k} \Omega$, additional resistance $\left(R_{\text {add }}\right)-6.8 \mathrm{k} \Omega$, external voltage $2.6 \mathrm{~V}$, voltage on the sample -0.3 to $1 \mathrm{~V}$.

The photoconductivity spectra of the macroporous silicon structure with the oxide layer thickness $30 \mathrm{~nm}$; silicon structures with $\mathrm{CdS}$ and $\mathrm{ZnO}$ nanocrystals on silicon oxide layer are presented in Figs 4 and 5. There is the high photon energy shift $0.17 \ldots 0.20 \mathrm{eV}$ in the main photoconductivity peak. The main peak in the photoconductivity spectra was measured for $\mathrm{ZnO}$ nanocoating on oxide of 7-nm thickness. The splitting of the main peak into two peaks with the distance between them, respectively, 65 and $70 \mathrm{meV}$ was measured for $\mathrm{CdS}$ and $\mathrm{ZnO}$ nanocoatings on oxide with the thickness $15 \mathrm{~nm}$. The splitting of the main peak by three ones with the distance between them, respectively, 65 and $70 \mathrm{meV}$ was measured for CdS nanocoating on oxide with the thickness $30 \mathrm{~nm}$. Spectra of the macroporous silicon structure with the oxide thickness $30 \mathrm{~nm}$ (Figs 4 and 5, curve 1) also hold the main peak splitting by three ones with a separation 70 and $80 \mathrm{meV}$.

The shift of the photoconductivity maxima of the investigated structures (Figs 4 and 5) to the higher photon energy side can be attributed to the quantum-sized effect. This shift was explained in $[10,11]$ by the quantum-sized effect in the transition from silicon matrix to $\mathrm{Si}$ nanoclusters in dielectric $\left(\mathrm{SiO}_{\mathrm{x}}\right)$. The value of the shift is consistent both with theoretical estimates for the energy gap and experimental photoluminescence peak for $\mathrm{Si}$ nanoclusters of the size $\leq 5 \mathrm{~nm}$ in the oxide environment. On the other hand, quantization of charge carriers in the near-surface region of silicon indicates strong enrichment of silicon surface by electrons and quantum well formation. Therefore, the shift of the main peak of photoconductivity to the higher photon energy can be explained by the band filling effect [9] and interband transitions of electrons to the Fermi level in the conduction band. Thus, the quantum energy levels are, respectively, $E_{0,1}=E_{1}+E_{\mathrm{F}}-E_{g}$ and $E_{1,2}=E_{2}+E_{\mathrm{F}}-E_{g}$.

Table 3. Parameters of silicon structures with nanocoatings and conditions of the photoconductivity spectra measurements.

\begin{tabular}{|c|c|c|c|c|c|c|}
\hline & $\begin{array}{c}\text { Nano- } \\
\text { particles }\end{array}$ & $\begin{array}{c}d_{\mathrm{SiO}_{2}}, \\
\mathrm{~nm}\end{array}$ & $\begin{array}{c}R_{\text {samp }}, \\
\mathrm{k} \Omega\end{array}$ & $\begin{array}{c}R_{\text {add }}, \\
\mathrm{k} \Omega\end{array}$ & $\begin{array}{c}\lambda_{\text {spectr. }}, \\
\mu \mathrm{m}\end{array}$ & $v, \mathrm{~Hz}$ \\
\hline 1 & $\mathrm{CdS}$ & 15 & 0.2 & 6.8 & $0.5-2$ & 317 \\
\hline 2 & $\mathrm{CdS}$ & 30 & 0.19 & 6.8 & $0.5-2$ & 310 \\
\hline 3 & $\mathrm{ZnO}$ & 7 & $\begin{array}{c}0.33 \\
0.34\end{array}$ & 6.8 & $0.5-2$ & 313 \\
\hline 4 & $\mathrm{ZnO}$ & 15 & 0.33 & 6.8 & $0.5-2$ & 317 \\
\hline 5 & $\mathrm{macPS}$ & 30 & $\begin{array}{c}2.6 \\
10.5\end{array}$ & 6.8 & $0.5-2$ & 317 \\
\hline
\end{tabular}

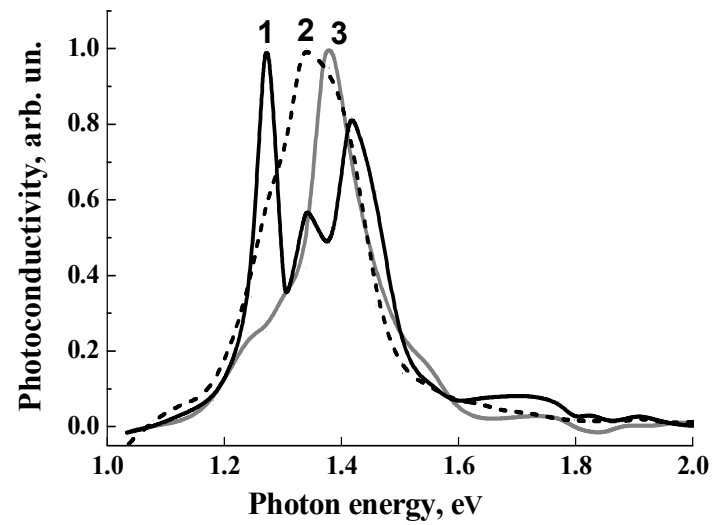

Fig. 4. Spectra of photoconductivity of the macroporous silicon structure with the oxide thickness $30 \mathrm{~nm}$ (1); silicon structures with CdS nanocrystals on silicon oxide layer of 15-nm (2) and 30-nm (3) thickness.

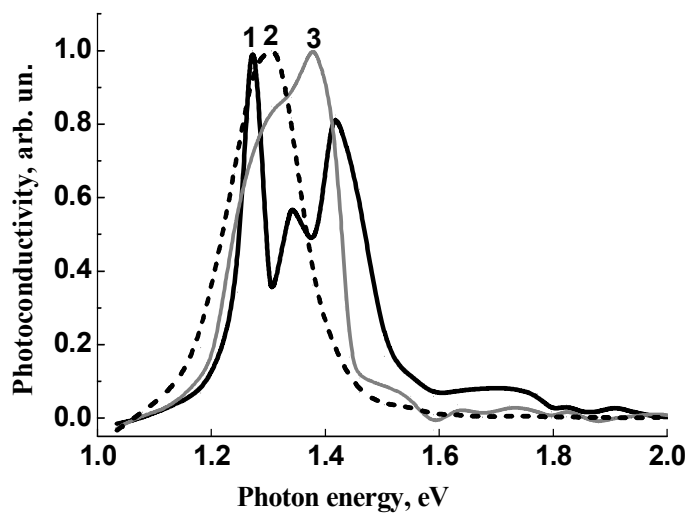

Fig. 5. Spectra of photoconductivity of the macroporous silicon structure with the oxide thickness $30 \mathrm{~nm}$ (1); silicon structures with $\mathrm{ZnO}$ nanocrystals on silicon oxide layer of 7-nm (2) and 15-nm (3) thickness.

The electric field intensity $F_{S}$ was determined on the basis of the model of the triangular potential well (Eq. (1)). And the electric field in the near-surface region of silicon with $\mathrm{CdS}$ nanocrystals is equal to $(0.8 \ldots 2) \cdot 10^{5} \mathrm{~V} / \mathrm{cm}$ for the first quantum level and $3 \cdot 10^{5} \mathrm{~V} / \mathrm{cm}$ for the second one. In the near-surface region of silicon with $\mathrm{ZnO}$ nanocrystals, $F_{S}$ is equal to $(2 \ldots 2.3) \cdot 10^{5} \mathrm{~V} / \mathrm{cm}$ for the first quantum level and $3 \cdot 10^{5} \mathrm{~V} / \mathrm{cm}$ for the second one. These data are lower than the $F_{S}$ values obtained via the Franz-Keldysh oscillations (Table 4).

The electric fields obtained from the electroreflectance (Franz-Keldysh effect and main peak splitting) and photoconductivity spectra (main photoconductivity peak splitting) are summarized in Table 5. The data obtained for the nanocoating of $\mathrm{CdS}$ nanocrystals on oxide with the thickness $30 \mathrm{~nm}$ are most correlated: $F_{S}=3.11 \cdot 10^{5} \mathrm{~V} / \mathrm{cm}$ (Franz-Keldysh effect); $F_{S}^{1,2}=3.05 \cdot 10^{5} \mathrm{~V} / \mathrm{cm}$ (quantization in the electroreflectance spectra); $\quad F_{S}^{1,2}=3.12 \cdot 10^{5} \mathrm{~V} / \mathrm{cm}$ (quantization in the photoconductivity spectra). For this 
Table 4. Fermi level in the conduction band $E_{\mathrm{F}}$, first quantum energy level $E_{0,1}$ and electric field $F_{S}{ }^{0,1}$, second quantum energy level $E_{1,2}$ and electric field $F_{S}^{1,2}$ obtained from the photoconductivity spectra.

\begin{tabular}{|c|c|c|c|c|c|c|}
\hline \multirow{2}{*}{ Sample } & \multirow{2}{*}{$\begin{array}{c}d_{\mathrm{SiO}_{2}}, \\
\mathrm{~nm}\end{array}$} & \multicolumn{6}{|c|}{ Photoconductivity } \\
\cline { 3 - 7 } & & $E_{\mathrm{F}}, \mathrm{eV}$ & $\begin{array}{c}E_{0,1}, \\
10^{-3} \mathrm{eV}\end{array}$ & $\begin{array}{c}F_{S}^{0,1}, \\
10^{5} \mathrm{~V} / \mathrm{cm}\end{array}$ & $\begin{array}{c}E_{1,2}, \\
10^{-3} \mathrm{eV}\end{array}$ & $\begin{array}{c}F_{S}^{1,2}, \\
10^{5} \mathrm{~V} / \mathrm{cm}\end{array}$ \\
\hline $\mathrm{macPS}$ & 30 & 1.27 & 70 & 2.07 & 80 & 3.43 \\
\hline $\mathrm{CdS}$ & 15 & 1.27 & 70 & 2.07 & - & - \\
\hline $\mathrm{CdS}$ & 30 & 1.24 & 65 & 1.85 & 75 & - \\
\hline $\mathrm{ZnO}$ & 7 & 1.31 & - & - & - & - \\
\hline $\mathrm{ZnO}$ & 15 & 1.31 & 65 & 1.85 & - & -12 \\
\hline
\end{tabular}

Table 5. The electric fields in $\mathrm{Si}_{-} \mathrm{SiO}_{2}$ boundary obtained from the electroreflectance and photoconductivity spectra.

\begin{tabular}{|c|c|c|c|c|c|}
\hline & Franz-Keldysh effect & \multicolumn{2}{|c|}{$\begin{array}{c}\text { Quantization } \\
\text { (electroreflectance) }\end{array}$} & \multicolumn{2}{c|}{ Quantization (photoconductivity) } \\
\hline$d_{\mathrm{SiO}_{2}}, \mathrm{~nm}$ & $\begin{array}{c}F_{S}, \\
10^{5} \mathrm{~V} / \mathrm{cm}\end{array}$ & $\begin{array}{c}F_{S}^{0,1} \\
10^{5} \mathrm{~V} / \mathrm{cm}\end{array}$ & $\begin{array}{c}F_{S}{ }^{1,2}, \\
10^{5} \mathrm{~V} / \mathrm{cm}\end{array}$ & $\begin{array}{c}F_{S}^{0,1}, \\
10^{5} \mathrm{~V} / \mathrm{cm}\end{array}$ & $\begin{array}{c}F_{S}{ }^{1,2}, \\
10^{5} \mathrm{~V} / \mathrm{cm}\end{array}$ \\
\hline CdS_15 & 6.65 & 0.762 & - & 2.07 & - \\
\hline CdS_30 & 3.11 & 1.93 & 3.05 & 1.85 & 3.12 \\
\hline ZnO_15 & 7.74 & 2.29 & - & - & - \\
\hline ZnO_30 & 4.35 & 2.02 & 3.05 & 1.85 & - \\
\hline
\end{tabular}

sample, the high photon energy shift $140 \mathrm{meV}$ is equal to the sum $E_{0,1}+E_{1,2}$ in the electroreflectance and photoconductivity spectra due to the interband transitions (direct and indirect) of electrons to the Fermi level in the conduction band.

\section{Conclusions}

The $\mathrm{Si}-\mathrm{SiO}_{2}$ interface in oxidized silicon structures with surface $\mathrm{CdS}$ and $\mathrm{ZnO}$ nanocrystals was investigated using the methods of electroreflectance and photoconductivity. The direct interband transition energy, broadening parameter and relaxation time of charge carriers were identified from the electroreflectance spectra of silicon structures with silicon oxide layer of 7, 15 and 30-nm thickness as well as $\mathrm{CdS}, \mathrm{ZnO}$ nanocrystals. There were revealed the Franz-Keldysh effect, built-in electric field and surface quantization of charge carriers in the $\mathrm{Si}-\mathrm{SiO}_{2}$ region. The broadening parameter for oxidized silicon with $\mathrm{CdS}$ and $\mathrm{ZnO}$ nanocoatings increases with the thickness of silicon oxide and is much higher than the value of $\Gamma$ for monocrystalline silicon, indicating the influence of defects on the interface of $\mathrm{Si}_{-}-\mathrm{SiO}_{2}$. The main electroreflectance peak indicates quantization of charge carriers in the near-surface region of silicon and splitting of peaks corresponding to one quantized energy level with the oxide thickness $15 \mathrm{~nm}$ and two quantum levels with the oxide thickness $30 \mathrm{~nm}$.

It was detected the splitting of photoconductivity peaks in the area of indirect band-to-band transition due to quantization of charge carriers in the surface silicon region, too. The splitting of the main peak by two peaks was measured for the nanocoating on oxide with the thickness $15 \mathrm{~nm}$. And the splitting of the main maximum by three peaks was measured for the nanocoating on oxide with the thickness $30 \mathrm{~nm}$. Quantization of charge carriers in the near-surface region of silicon indicates strong enrichment of silicon surface by electrons and quantum well formation. Therefore, the shift of the main peak of photoconductivity to the higher photon energy can be explained by the band filling effect and interband transitions of electrons to the Fermi level in the conduction band.

The electric fields obtained using the electroreflectance and photoconductivity spectra are most correlated for the nanocoating of CdS nanocrystals with the oxide thickness $30 \mathrm{~nm}$. For this structure, the high photon energy shift is equal to the sum $E_{0,1}+E_{1,2}$ in the electroreflectance and photoconductivity spectra due to the interband transitions (direct and indirect) of electrons to the Fermi level in the conduction band. 


\section{References}

1. L.A. Karachevtseva, S.Ya. Kuchmii, A.L Stroyuk, O.O. Lytvynenko, O.E. Raevska, O.Yu. Kolesnyk, G.Ya. Grodzyuk and O.J. Stronska, Photoluminescence of macroporous silicon structures with $\mathrm{SiO}_{2}$ layers and $\mathrm{CdS}$ nanocrystals // Modern information and electronic technologies, Astroprint, Odesa, p. 183-185, 2013.

2. A. Birner, R.B. Wehrspohn, U.M. Gosele and K. Busch, Silicon-based photonic crystals // Adv. Mater. 13, p. 377-388 (2001).

3. L.A. Karachevtseva, Two-dimensional photonic crystals as perspective materials of modern nanoelectronics // Semiconductor Physics, Quantum Electronics \& Optoelectronics, 7, p. 430-435 (2004).

4. A. Glushko and L. Karachevtseva, PBG properties of three-component 2D photonic crystals // Photonics and Nanostructures, 4, p. 141-145 (2006).

5. L.A. Karachevtseva, V.I. Ivanov, O.O. Lytvynenko, K.A. Parshin and O.J. Stronska, The impurity Franz-Keldysh effect in 2D photonic macroporous silicon structures // Appl. Surf. Sci. 255, p. 3328-3331 (2008).
6. 7. L. Karachevtseva, S. Kuchmii, O. Lytvynenko, F. Sizov, O. Stronska and A. Stroyuk, Oscillations of light absorption in 2D macroporous silicon structures with surface nanocoatings // Appl. Surf. Sci. 257, p. 3331-3335 (2011).

7. L.A. Karachevtseva, S.Ya. Kuchmii, K.P. Konin, O.O. Lytvynenko, A.L Stroyuk, Room temperature Wannier-Stark effect in 2D macroporous silicon structures with nanocoatings // Chemistry, Physics and Technology of Surface, 2, p. 105-113 (2011).

8. N. Chestnoy, T.D. Harris, R. Hull, L.E. Brus, Luminescence and photophysics of cadmium sulfide semiconductor clusters: The nature of the emitting electronic state // J. Phys. Chem. 90(15), p. 3393-3399 (1986).

9. $\mathrm{P} . \mathrm{Yu}$ and $\mathrm{M}$. Cardona, Fundamentals of Semiconductors: Physics and Materials Properties. Springer-Verlag, Berlin, Heidelberg, 1999.

10. A.A. Evtukh, Investigation of electron and hole tunneling through thin dioxide films // Ukr. Phys. J. 46(1), p. 1087-1093 (2001).

11. N.A. Hill, K.B. Whaley, A theoretical study of light emission from nanoscale silicon // J. Electron. Mater. 25(2), p. 269-285 (1996). 